Research Article

\title{
Development of Innovative Polymer-Based Matricial Nanostructures for Ritonavir Oral Administration
}

\author{
Mosiele Giaretta, ${ }^{1}$ Mariana Domingues Bianchin, ${ }^{2}$ Luiz Alberto Kanis, ${ }^{3}$ \\ Renata Vidor Contri ${ }^{D}{ }^{4}{ }^{4}$ and Irene Clemes Külkamp-Guerreiro $\mathbb{i D}^{1,2,4}$ \\ ${ }^{1}$ Programa de Pós-Graduação em Ciências Farmacêuticas, Universidade Federal do Rio Grande do Sul, Brazil \\ ${ }^{2}$ Programa de Pós-Graduação em Farmacologia e Terapêutica, Universidade Federal do Rio Grande do Sul, Brazil \\ ${ }^{3}$ Programa de Pós-Graduação em Ciências da Saúde, Universidade do Sul de Santa Catarina, Brazil \\ ${ }^{4}$ Faculdade de Farmácia, Universidade Federal do Rio Grande do Sul, Brazil
}

Correspondence should be addressed to Renata Vidor Contri; renata.contri@gmail.com

and Irene Clemes Külkamp-Guerreiro; irene@ufrgs.br

Received 29 September 2018; Accepted 23 December 2018; Published 26 February 2019

Academic Editor: Surinder Singh

Copyright (c) 2019 Mosiele Giaretta et al. This is an open access article distributed under the Creative Commons Attribution License, which permits unrestricted use, distribution, and reproduction in any medium, provided the original work is properly cited.

\begin{abstract}
Ritonavir is used in the treatment of pediatric human immunodeficiency virus infection. The aim of this study was to develop and evaluate innovative polymer-based matricial nanostructures containing ritonavir for a sustained delivery. Two formulations were prepared by interfacial deposition of preformed polymers using Eudragit ${ }^{\circledR}$ RS100 in combination with Polycaprolactone triol 300 $\left(\mathrm{NP}_{\mathrm{R}}-300\right)$ or Polycaprolactone triol $900\left(\mathrm{NP}_{\mathrm{R}}-900\right)$. Ritonavir $\left(1 \mathrm{mg} \mathrm{mL} \mathrm{mL}^{-1}\right)$ was incorporated in the formulations. $\mathrm{NP}_{\mathrm{R}}-300 \mathrm{showed}$ a mean size of $559 \mathrm{~nm}$, SPAN of 1.66, zeta potential of $5.9 \mathrm{mV}, \mathrm{pH}$ of 4.23 , drug content of $73 \%$, and stability under storage for 15 days. $\mathrm{NP}_{\mathrm{R}}-900$ showed a mean size of $120 \mathrm{~nm}$, SPAN of 0.83 , zeta potential of $7.0 \mathrm{mV}, \mathrm{pH}$ of 4.2 , drug content of $81 \%$, and stability under storage for 60 days. The ritonavir content was 100\% incorporated in both formulations. TEM images demonstrated spherical matricial structures. The ritonavir release in the simulated gastric medium was controlled by incorporation into the nanoparticles, especially into $\mathrm{NP}_{\mathrm{R}}-900$. The formulations showed mucoadhesive properties, and the taste evaluation by an in vivo sensory panel indicated that particle size might influence taste perception since the formulation with the larger size of the nanoparticles $\left(\mathrm{NP}_{\mathrm{R}}-300\right)$ worsened the taste of the suspension. The $\mathrm{NP}_{\mathrm{R}}-900$ was the most promising nanoparticle formulation for oral delivery of ritonavir.
\end{abstract}

\section{Introduction}

By 2016, approximately 36.7 million people were living with HIV worldwide, of whom $54 \%$ of adults and $43 \%$ of children received antiretroviral therapy throughout their lives [1]. The drugs for antiretroviral therapy include different classes, and among them are protease inhibitors. Ritonavir is a protease inhibitor, often prescribed in combination with other antiretroviral substances, which prevent the replication of HIV virus by blocking the action of protease enzymes [2].

Considering the antiretroviral treatment in children, adherence to therapy is directly linked to some very important factors, such as the taste of the drug and the number of daily doses. Thus, drugs with an unpleasant taste may reduce adherence to the treatment and, therefore, compromise the success of antiretroviral therapy in children [3]. Acceptable palatability is a requirement for pediatric formulations. Oral administration of bitter-tasting drugs is a matter of concern in the treatment of children. The nanotechnological approach is an alternative to mask the bitter taste, increasing the adherence of children to treatment $[4,5]$.

Nanotechnology is also widely used to control drug release. As far as prolonged release is concerned, polymeric nanoparticles have been extensively studied in the last decades, becoming an important strategy in the field of drug delivery. Its purpose is to increase the duration of the release, achieve a different mechanism, or delay the initial release [6]. Polymeric nanoparticles have been cited as one kind of 
nanomedicine that can be advantageous for the treatment of HIV [7, 8].

Among the polymers used for nanoparticle production, Eudragit ${ }^{\circledR}$ RS100 should be highlighted. Such a polymer presents cationic properties, good stability, and a capability for swelling and slowly releasing the drug [9]. However, nanoparticles composed only of Eudragit ${ }^{\circledR}$ RS100 as the polymer forming the matricial structure may show limited drug encapsulation, as shown by Dillen et al. [10] who achieved the encapsulation of ciprofloxacin with only $60 \%$ of drug loading. The high hydrophilicity and surface charge of Eudragit ${ }^{\circledR}$ RS100 are pointed out as the reasons for the low encapsulation of hydrophobic substances [11].

The polycaprolactone triol polymer is a biodegradable aliphatic polyester, with moderate water solubility due to the low molecular weight and the hydroxyl groups in the molecule. Recent studies demonstrate that such a polymer, when combined with others, may provide a plastification effect to the system, implying a prolonged release of the drug [12]. As far as it is known, the polycaprolactone triol polymers have never been used to prepare nanoparticles.

Therefore, the present investigation reports the development of innovative polymer-based matricial nanostructures, based on a combination of Eudragit ${ }^{\circledR}$ RS100 with two types of polycaprolactone triol (Polycaprolactone triol 300 and Polycaprolactone triol 900). The antiretroviral drug ritonavir was incorporated aiming at controlling drug release and masking the bitter taste.

\section{Materials and Methods}

2.1. Materials. Ritonavir (RIT) was generously supplied by Cristalia $^{\circledR}$. Polycaprolactone triol 900 (PCLT 900), Polycaprolactone triol 300 (PCLT 300), and mucin type II were obtained from Sigma-Aldrich ${ }^{\circledR}$. Eudragit ${ }^{\circledR}$ RS100 (EUD) was generously supplied by Evonik ${ }^{\circledR}$ (Germany). Polysorbate 80 , acetone, and methanol (HPLC grade) were obtained from Synth ${ }^{\circledR}$ (Brazil), Exxodo Científica ${ }^{\circledR}$ (Brazil), and PanReac ${ }^{\circledR}$ AppliChem, respectively. Sodium chloride, pepsin, and hydrochloric acid were purchased from Neon ${ }^{\circledR}$. All other solvents and reagents used were of analytical grade and all reagents were used as received.

2.2. Preformulation Evaluation. Before preparing the matricial nanostructures, two preformulation studies were performed. At first, the solubility of RIT in the liquid (PCLT 300) and semisolid (PCLT 900) polymers was evaluated, in order to predict the drug incorporation into the system. The mixtures (1:9 drug: polymer) were heated to $70^{\circ} \mathrm{C}$ for 60 minutes, and the melts were observed to verify whether the drug was soluble or not in the polymers tested [13].

Then, a polymer swelling experiment was performed in order to verify the influence of the liquid (PCLT 300) and semisolid (PCLT 900) polymers in the EUD structure. Polymeric films were prepared by the solubilization of $2 \mathrm{~g}$ of EUD in acetone, followed by the evaporation of the solvent at room temperature.

Small pieces of the films were cut, weighed, and submerged in PCLT 300 and PCLT 900 for 30 days. On the first and 30th days, the films were dried with soft paper and weighed [14].

2.3. Preparation of Matricial Nanostructures. The formulations were prepared by the interfacial deposition of preformed polymer method [15], using EUD in combination with PCLT 300 or PCLT 900. The suspensions were named $\mathrm{NP}_{\mathrm{R}}-300$ and $\mathrm{NP}_{\mathrm{R}}-900$, respectively (Table 1 ). After component solubilization, the organic phase was injected into the aqueous phase and kept under magnetic stirring at $37^{\circ} \mathrm{C}$ for 10 minutes. The solvents were removed, and the suspensions were concentrated under reduced pressure (rotary evaporation) until the final volume $(10 \mathrm{~mL})$ was attained, which was then adjusted with ultrapure water. Nanoparticles without RIT $\left(\mathrm{NP}_{\mathrm{B}}-300\right.$ and $\left.\mathrm{NP}_{\mathrm{B}}-900\right)$ were prepared in the same way, only that the drug was omitted.

2.4. Particle Size and Size Distributions. The particle size and the size distribution formulations were evaluated by laser diffraction (Mastersizer ${ }^{\circledR}$ 2000, Malvern Instruments Ltd.). The sample was inserted in the recipient containing distilled water, without prior dilution. The particle size values were expressed in terms of their mean diameter $(D(3,4))$ and their size distribution values (Span (equation (1))), both calculated by volume $(v)$ and by number $(n)$ of particles.

$$
\operatorname{Span}=\frac{\left(D_{0.9}-D_{0.1}\right)}{D_{0.5}}
$$

where $D_{0.1}, D_{0.5}$, and $D_{0.9}$ refer to the diameter corresponding to $10 \%, 50 \%$, and $90 \%$ of the cumulative distribution, respectively.

2.5. Zeta Potential. The zeta potential was determined by analyzing electrophoretic mobility Zetasizer ${ }^{\circledR}$, Malvern Instruments Ltd.) by the predilution of the samples 500 -fold in a $10 \mathrm{mM} \mathrm{NaCl}$ aqueous solution that was previously filtered $(0.45 \mu \mathrm{m})$.

2.6. $\mathrm{pH}$ Measurements. The $\mathrm{pH}$ values were determined directly in the formulation through the calibrated potentiometer DM-22 (Digimed ${ }^{\circledR}$ ) that was previously calibrated ( $\mathrm{pH} 4$ and 7).

2.7. RIT Content and Incorporation Efficiency. RIT was quantified by a high-performance liquid chromatography (Perkin Elmer ${ }^{\circledR}$ S-200) method with UV detection (HPLC-UV) using a C18 Phenomenex ${ }^{\circledR}$ column $(150 \mathrm{~mm} \times 4.0 \mathrm{~mm}, 4 \mu \mathrm{m})$, Guard Column SecurityGuard cartridges for Phenomenex C18 columns, mobile phase using methanol: water $(67: 33 \mathrm{v} / \mathrm{v})$, flow of $1.2 \mathrm{~mL} \mathrm{~min}^{-1}, \lambda$ of $239 \mathrm{~nm}$, injection volume of $20 \mu \mathrm{L}$, and retention time of $11 \mathrm{~min}$. The method specificity was evaluated by analyzing blank nanoparticle interference, the linearity by five different concentrations $\left(15,20,25,30\right.$, and $\left.35 \mu \mathrm{g} \mathrm{mL} L^{-1}\right)$, repeatability with six samples in the same concentration, and inter-day precision with sample analysis in two different days. The accuracy was determined by the drug solution added in blank nanoparticles and drug recovery analysis. The RIT total content in the formulations was determined by sample dilution in the 
TABLE 1: Composition of nanoparticles $\left(E U D=\right.$ Eudragit $^{\circledR}$ RS100, PCLT $=$ polycaprolactone triol, and RIT $=$ ritonavir $)$.

\begin{tabular}{lcc}
\hline & $\mathrm{NP}_{\mathrm{R}}-300$ & $\mathrm{NP}_{\mathrm{R}}-900$ \\
\hline Aqueous phase & & \\
Polysorbate 80 (mg) & 76 & 76 \\
Water (mL) & 54 & 54 \\
Organic phase & & \\
EUD (mg) & 100 & 100 \\
PCLT 300 (mg) & 330 & - \\
PCLT 900 (mg) & - & 330 \\
Acetone (mL) & 27 & 27 \\
RIT (mg) & 10 & 10 \\
\hline
\end{tabular}

mobile phase to the RIT theoretical concentration of $25 \mu \mathrm{g} \mathrm{mL}^{-1}$. The diluted samples were shaken for 2 minutes, filtered $(0.45 \mu \mathrm{m}$, Chromafil, Germany), and analyzed by the HPLC-UV method as reported before. The RIT total content was expressed as a percentage of the theoretical concentration.

The RIT incorporation efficiency (IE) was determined by the ultrafiltration-centrifugation technique. An aliquot of the sample was placed in a filter unit (Millipore $10,000 \mathrm{Da}$, Microcon ${ }^{\circledR}$ ) and subjected to centrifugation at $1884 \times \mathrm{g}$ for 10 minutes. Thus, the nanoparticles were retained and the non-associated (free) drug that passed through the filter (ultrafiltrate) was directly injected for quantification in HPLC-UV. The IE was expressed as a percentage (relative) from the ratio between the concentration in the dispersed phase, the difference between the total concentration of RIT in the formulation (Ct), and the free concentration of RIT in the continuous phase $(\mathrm{Cl})$ according to equation (2):

$$
\mathrm{IE}=100 \times \frac{\mathrm{Ct}-\mathrm{Cl}}{\mathrm{Ct}}
$$

2.8. Transmission Electron Microscopy. Transmission electron microscopy (TEM) was used to evaluate the morphology of the RIT nanoparticles. The analyses were carried out at the Microscopy and Microanalysis Center of the Federal University of Rio Grande do Sul (UFRGS). Each sample was diluted $(1: 10 \mathrm{v} / \mathrm{v})$ and deposited on copper grids. An aqueous solution of uranyl acetate $2 \%$ was used as negative contrast.

2.9. Storage Stability Studies. The nanoparticle formulations were maintained in amber glass flasks, at room temperature for 60 days. At predetermined times ( $0,15,30$, and 60 days), the suspensions were analyzed in terms of particle sizes, size distributions, zeta potential, $\mathrm{pH}$, and RIT total content by the same methodologies as mentioned before.

2.10. In Vitro Drug Release Profiles. The drug release in simulated gastric medium ( $\mathrm{pH} 1.2$ ) of RIT nanoparticles and free RIT solution (methanolic solution of the drug) was performed at $37^{\circ} \mathrm{C}$ under magnetic stirring. To prepare the medium, sodium chloride $(2.0 \mathrm{~g})$, pepsin $(3.2 \mathrm{~g})$, and $37 \%$ hydrochloric acid $(7 \mathrm{~mL})$ were dissolved in an aqueous solution $(1000 \mathrm{~mL})$. RIT nanoparticle formulation and RIT solution were placed on dialysis tubing membranes (typical molecular weight cutoff $=14,000$ ), observing the sink condition previously calculated. Samples were withdrawn at predetermined times up to 96 hours, filtered, and analyzed by the HPLC-UV method previously described. The experiment was performed in triplicate.

Data obtained by the in vitro release experiments were mathematically modeled using Scientist ${ }^{\circledR} 2.0$ (MicroMath $^{\circledR}$, USA). The experimental points were fitted to first order monoexponential and first order biexponential (equations (3) and (4), respectively).

$$
\begin{aligned}
& C=100-\left[C_{0} e^{-k t}\right], \\
& C=100-\left[A e^{-\alpha t}+B e^{-\beta t}\right],
\end{aligned}
$$

where $C$ is the percentage of RIT released on time $(t)$ in minutes, $C_{0}$ is the total RIT content in percentage, and $k, \alpha$, and $\beta\left(\mathrm{min}^{-1}\right)$ are the observed kinetic rate constants. The best model was analyzed considering the best fit of data to graphic profile, correlation between the experimental and theoretical values $(r)$, and the value of the model selection criteria (MSC).

The flux $J\left(\mathrm{mg} \mathrm{cm}^{-2} \mathrm{~h}^{-1}\right)$ was determined from the slope of the linear region of the plot of the cumulative amount of the released drug $M_{t}$ as a function of time $t$ (equation (5)), according to Fick's first law of diffusion.

$$
M_{t}=M_{0}-S J \cdot t
$$

where $S$ is the surface area $\left(\mathrm{cm}^{3}\right)$ of the dialysis bag and $M_{0}$ (mg) is the total amount of drug.

2.11. Mucoadhesiveness. An aqueous solution containing mucin $0.25 \%(\mathrm{w} / \mathrm{v})$ was prepared under magnetic stirring at room temperature. Aliquots of nanoparticles were mixed with the mucin solution $(1: 1)$ at $37^{\circ} \mathrm{C}$ for 2 hours. These samples were evaluated regarding average size, polydispersion (PDI), and zeta potential [16] (Zetasizer ${ }^{\circledR}$, Malvern Instruments Ltd.). The mucoadhesion index (MI) was calculated according to equation (6).

$$
\mathrm{MI}=\frac{\mathrm{Dh} 2}{\mathrm{Dh} 0},
$$

where $\mathrm{Dh} 0$ and $\mathrm{Dh} 2$ are the average sizes of particles before and after the contact with mucin, respectively. The experiment was performed in triplicate.

2.12. Taste Evaluation In Vivo. The taste was evaluated by a discriminatory sensory analysis, carried out in accordance with Brazilian legislation, after obtaining the approval of the Research Ethics Committee, regulated by the National Research Ethics Council. The RIT nanoparticle formulations, as well as the RIT solution (ethanolic solution of the drug), were prepared and identified with codes. Ten volunteers aged 20-33 years old were recruited and were provided with 
TABLE 2: Mean diameter $(D(4,3))$ by volume and number of particles, size distribution values (Span) by volume and number of particles, zeta potential, and $\mathrm{pH}$ values of nanoparticles $\left(\mathrm{NP}_{\mathrm{R}}=\right.$ nanoparticles containing ritonavir, $\mathrm{NP}_{\mathrm{B}}=$ nanoparticles without ritonavir).

\begin{tabular}{lccccrc}
\hline Formulation & $D(4,3)_{(v)}(\mathrm{nm})$ & $\operatorname{Span}_{(v)}$ & $D(4,3)_{(n)}(\mathrm{nm})$ & $\operatorname{Span}_{(n)}$ & Zeta potential $(\mathrm{mV})$ & $\mathrm{pH}$ \\
\hline $\mathrm{NP}_{\mathrm{B}}-300$ & $576 \pm 23^{\mathrm{a}}$ & $1.60 \pm 0.08^{\mathrm{a}}$ & $559 \pm 21^{\mathrm{a}}$ & $1.35 \pm 0.09^{\mathrm{a}}$ & $+5.9 \pm 0.0^{\mathrm{a}}$ & $4.25 \pm 0.02^{\mathrm{a}}$ \\
$\mathrm{NP}_{\mathrm{R}}-300$ & $559 \pm 74^{\mathrm{a}}$ & $1.66 \pm 0.01^{\mathrm{a}}$ & $544 \pm 66^{\mathrm{a}}$ & $1.28 \pm 0.15^{\mathrm{a}}$ & $+5.9 \pm 1.2^{\mathrm{a}}$ & $4.23 \pm 0.01^{\mathrm{a}}$ \\
$\mathrm{NP}_{\mathrm{B}}-900$ & $120 \pm 1^{\mathrm{b}}$ & $0.83 \pm 0.00^{\mathrm{b}}$ & $120 \pm 2^{\mathrm{b}}$ & $0.77 \pm 0.01^{\mathrm{b}}$ & $+8.5 \pm 2.1^{\mathrm{a}}$ & $4.19 \pm 0.03^{\mathrm{a}}$ \\
$\mathrm{NP}_{\mathrm{R}}-900$ & $120 \pm 5^{\mathrm{b}}$ & $0.83 \pm 0.01^{\mathrm{b}}$ & $121 \pm 7^{\mathrm{b}}$ & $0.77 \pm 0.03^{\mathrm{b}}$ & $+7.0 \pm 1.3^{\mathrm{a}}$ & $4.21 \pm 0.02^{\mathrm{a}}$ \\
\hline
\end{tabular}

${ }^{a-c}$ Different letters within the same column indicate significant differences at $p<0.05$.

guidance on the study. After signing the free and informed consent terms, each volunteer kept $0.5 \mathrm{~mL}$ of formulation in the mouth for 15 seconds and then spat out. The volunteers completed a questionnaire after tasting each formulation, evaluating the level of bitterness. Between each assessment, water and a cracker were given to the subjects as a palate cleanser. The questionnaires were evaluated regarding the taste detected by the volunteers.

2.13. Statistical Analysis. The results were analyzed for statistical significance by one-way analysis of variance (ANOVA) followed by the Tukey test (for three or more groups) or the $t$-test (two groups), using the software GraphPad, with a significance level of 0.05 .

\section{Results and Discussion}

3.1. Preformulation Evaluation. The drug solubility test is the initial step when formulating. For this issue, the solubility of the drug was evaluated. The drug was considered soluble in the PCLT 300 and PCLT 900 polymers.

The compatibility of the polycaprolactone triol polymers with the EUD was evaluated after 30 days. The initial mass of the EUD polymeric film was $13.1 \pm 0.3 \mathrm{mg}$ and $14.4 \pm 0.6 \mathrm{mg}$ for PCLT 300 and PCLT 900, respectively. After 30 days, the polymer films weighed $13.4 \pm 0.6 \mathrm{mg}$ and $14.3 \pm 0.7 \mathrm{mg}$. From day one to day 30 , the statistical analysis showed that the difference was not significant $(p<0.05)$, indicating that the mixture of the PCLT polymers and EUD may be suitable for the preparation of nanoparticles.

3.2. Nanoparticle Formulations. Two nanoparticles were developed by different organic phase component combinations and an aqueous phase with polysorbate 80 . The organic phase was composed of combinations of the EUD polymer and other polymers: PCLT 300 or PCLT 900 at the proportions of 1.0 (EUD) to 3.3 (PCLT 300 or PCLT 900). The obtainment of the final formulations without ethanol and sugar is important in pediatric therapy.

The macroscopic aspect of the formulations was white homogeneous liquids without any precipitate. All formulations showed nanometric size, low Span value, and unimodal distribution profiles expressed by volume and number, which demonstrated the homogeneity of the suspensions. Also, there was no change in these parameters after the addition of RIT (Table 2).
The nanoparticles prepared with PCLT 300 presented greater size and Span values than PCLT 900 nanoparticles by the analysis of the volume and number of particles. The zeta potential was positive for all formulations, in accordance with the cationic nature of the EUD, which is a copolymer of poly(ethylacrylate, methyl-methacrylate methacrylic acid ester), which present ammonium quaternary groups [14, 17-19]. The cationic charge is appropriate to prevent lysosomal degradation and ensures the intracellular concentration of the drug [20].

The $\mathrm{pH}$ values were slightly acidic, in accordance with other nanostructures prepared using a similar method [21, 22].

The HPLC-UV method proved to be specific for RIT and linear between 15 and $35 \mu \mathrm{g} \mathrm{mL}^{-1} \quad(r=0.9976)$. Method precision was demonstrated by a relative standard deviation value of $3.6 \pm 0.03 \%$ and $1.77 \pm 0.02 \%$ for repeatability and intermediate precision, respectively. The accuracy showed a recovery of $100 \pm 2.9 \%$.

$\mathrm{NP}_{\mathrm{R}}-300$ and $\mathrm{NP}_{\mathrm{R}}-900$ presented the RIT contents of $73 \pm 3.2 \%$ and $81 \pm 0.6 \%$ and IE of $100 \%$ in both formulations. The analyses of the formulations under polarized light microscopy did not show the presence of crystals. The IE results of all formulations are higher than those described for nanoparticles prepared from different methods and compositions, which report about $93 \%$ and $89 \%$ of RIT encapsulated in nanoparticles [23, 24]. Destache et al. [25] developed PLGA nanoparticles containing RIT and two other antiretroviral drugs, and the RIT encapsulation efficiency was only $38 \%$. Thus, the method and the innovative combination of Eudragit ${ }^{\circledR}$ RS100 and PCLT proposed for the preparation of RIT nanoparticles were suitable and very efficient for the incorporation of this highly hydrophobic drug.

The morphology of the formulations can be visualized in Figure 1. The TEM images of formulations showed spherical nanoparticles and size results consistent with those of the laser diffraction technique. The formulations presented a matrix structure.

3.3. Storage Stability Study. After the preparation, the nanoparticles were maintained under storage at room temperature and were analyzed after 15, 30, and 60 days (Figure 2$)$. The mean diameter of all nanoparticles $(D(3,4))$ by volume and number of particles remained stable during the storage time (Figures 2(a) and 2(b)), as well as the unimodal size distribution and the maintenance of Span value lower than 2 


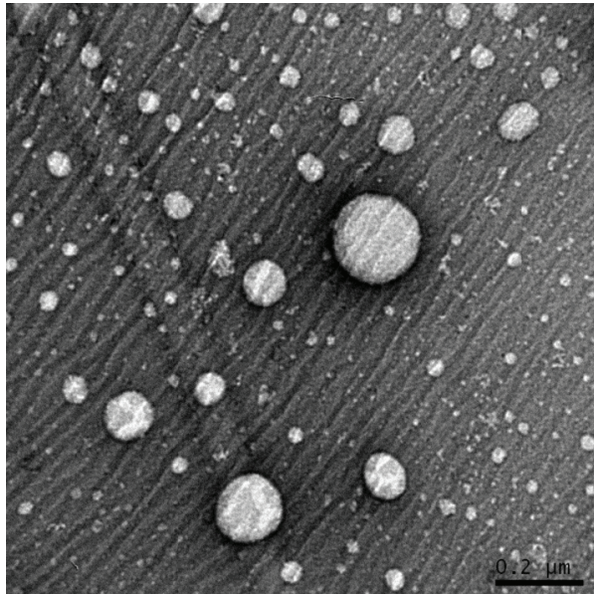

(a)

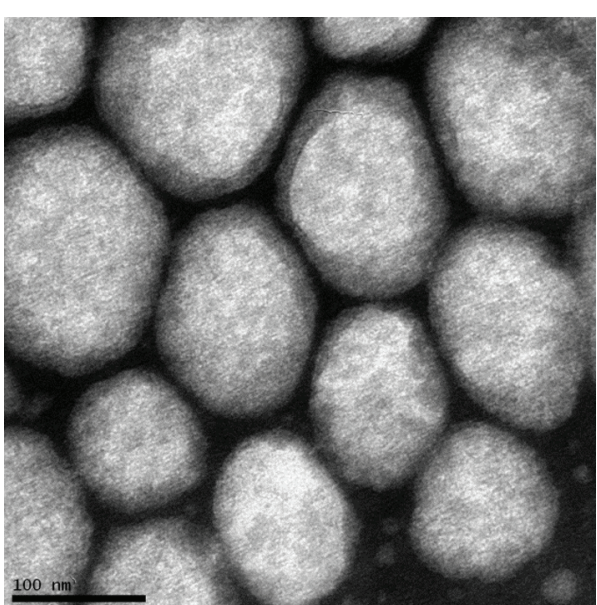

(b)

Figure 1: TEM images of (a) $\mathrm{NP}_{\mathrm{R}}-300 \times 100 \mathrm{~K}$ and (b) $\mathrm{NP}_{\mathrm{R}}-900 \times 300 \mathrm{~K}\left(\mathrm{NP}_{\mathrm{R}}=\right.$ nanoparticles containing ritonavir $)$.

(Figures 2(c) and 2(d)). The zeta potential values did not show variations for $\mathrm{NP}_{\mathrm{R}}-900$, while for $\mathrm{NP}_{\mathrm{R}}-300$ there were significant changes after 15 days $(p<0.05)$. Concerning the $\mathrm{pH}$, only $\mathrm{NP}_{\mathrm{R}}-300$ showed a slight reduction after 15 days of storage $(p<0.05)$ (Figure $2(\mathrm{f})$ ). RIT content did not change during 60 days for both formulations (Figure 2(g)).

$\mathrm{NP}_{\mathrm{R}}-900$ was able to maintain the stability of the RIT content during 60 days of storage while preserving the parameters analyzed, while for $\mathrm{NP}_{\mathrm{R}}-300$ slight changes in zeta potential and $\mathrm{pH}$, besides visual phase-separation, were observed after 15 days. Therefore, $\mathrm{NP}_{\mathrm{R}}-900$ was considered stable for 60 days, while $\mathrm{NP}_{\mathrm{R}}-300$ was stable for only 15 days under storage.

3.4. In Vitro RIT Release Profile. The percentages of in vitro RIT release from nanoparticles and RIT solution in terms of percentage as a function of time, up to $96 \mathrm{~h}$, are shown in Figure 3. The RIT methanolic solution released $104.9 \pm$ $3.2 \%$ in the release medium after $12 \mathrm{~h}$, while at the same period, $\mathrm{NP}_{\mathrm{R}}-300$ and $\mathrm{NP}_{\mathrm{R}}-900$ released $60.3 \pm 2.8 \%$ and $30.0 \pm 5.5 \%$, respectively. The RIT content released from nanoparticles in $12 \mathrm{~h}$ was statistically different from the methanolic solution $(p<0.05)$, demonstrating the ability of the nanoparticles to promote controlled release. Among the nanoparticles, the total amount of RIT released after $12 \mathrm{~h}$ by $\mathrm{NP}_{\mathrm{R}}-300$ was greater than by $\mathrm{NP}_{\mathrm{R}}-900$. Thus, in addition to the system type, the molecular weight of the polymer composing the polymeric core also influenced the RIT release. The higher molecular weight of the PCLT, the slower the release. These results suggested that the higher molecular weight in the core promoted the better structural stability of the formulation, which justifies the greater stability and control of the release.

The mathematical modeling of data obtained from in vitro RIT release of all formulations and solution presented the best parameters of the correlation coefficient $(r)$ and model selection criteria (MSC) when fitted by a monoexponential equation (Table 3). The apparent kinetic constant $(k)$ values presented by the nanoparticles were significantly lower $(p<0.05)$ than that determined for the drug in the solution (Table 3). These $k$ results, as well as the dialyzed profiles, demonstrate the ability of nanoparticles to control drug release in the gastric fluid.

The RIT release mechanism from the nanoparticles was investigated by the power law. The diffusional exponent $(n)$ values obtained were $0.51 \pm 0.01$ and $0.45 \pm 0.01$ for $\mathrm{NP}_{\mathrm{R}}-300$ and $\mathrm{NP}_{\mathrm{R}}-900$, respectively. For spherical geometry systems, the diffusional exponent values obtained for PCLT nanoparticles indicate anomalous transport, where both polymer relaxation and drug diffusion contribute to the drug release from the nanoparticles.

The controlled release of RIT promoted by nanoparticles is also evident by the significant $(p<0.05)$ flux reduction from $16.9 \pm 4.7 \mu \mathrm{g} \mathrm{cm}^{-2} \mathrm{~min}^{-1}$ (RIT solution) to $4.5 \pm 0.3$ and $3.0 \pm 0.1 \mu \mathrm{g} \mathrm{cm}^{-2} \mathrm{~min}^{-1}\left(\mathrm{NP}_{\mathrm{R}}-300\right.$ and $\mathrm{NP}_{\mathrm{R}}-900$, respectively).

3.5. Mucoadhesiveness. The mucoadhesive properties of the nanoparticles were assessed by the ability to interact with mucin from porcine stomach (type II). Mucin, one of the main components of the mucus layer, is a glycoprotein responsible for its viscoelastic gel properties that is directly involved in adhesion phenomena. Human mucin and animal mucin have similar chemical and morphological characteristics $[17,26,27]$. The porcine gastric mucin was suggested by Teubl et al. [27] as a model of human mucin.

The interaction between nanoparticles and mucin were evaluated by particle size and zeta potential analyses before and after contact. The mucin solution had a micrometer size, while the nanoparticles had average sizes of $571 \pm 12 \mathrm{~nm}$ and $123 \pm 2.4 \mathrm{~nm}$ for $\mathrm{NP}_{\mathrm{B}}-300$ and $\mathrm{NP}_{\mathrm{B}}-900$ (Figure 4(a)), respectively, before contact with the mucin. All nanoparticles presented unimodal distribution profiles with PDI values lower than 0.31 .

After the contact with mucin, $\mathrm{NP}_{\mathrm{B}}-300$ and $\mathrm{NP}_{\mathrm{B}}-900$ presented bimodal distribution profiles with a main peak in the nanometric range similar to that shown for the nanoparticle before the contact and other small peaks in the micrometer range, probably referring to free mucin (Figure 4(b)). The average size and PDI observed for $\mathrm{NP}_{\mathrm{B}}-300$ and 

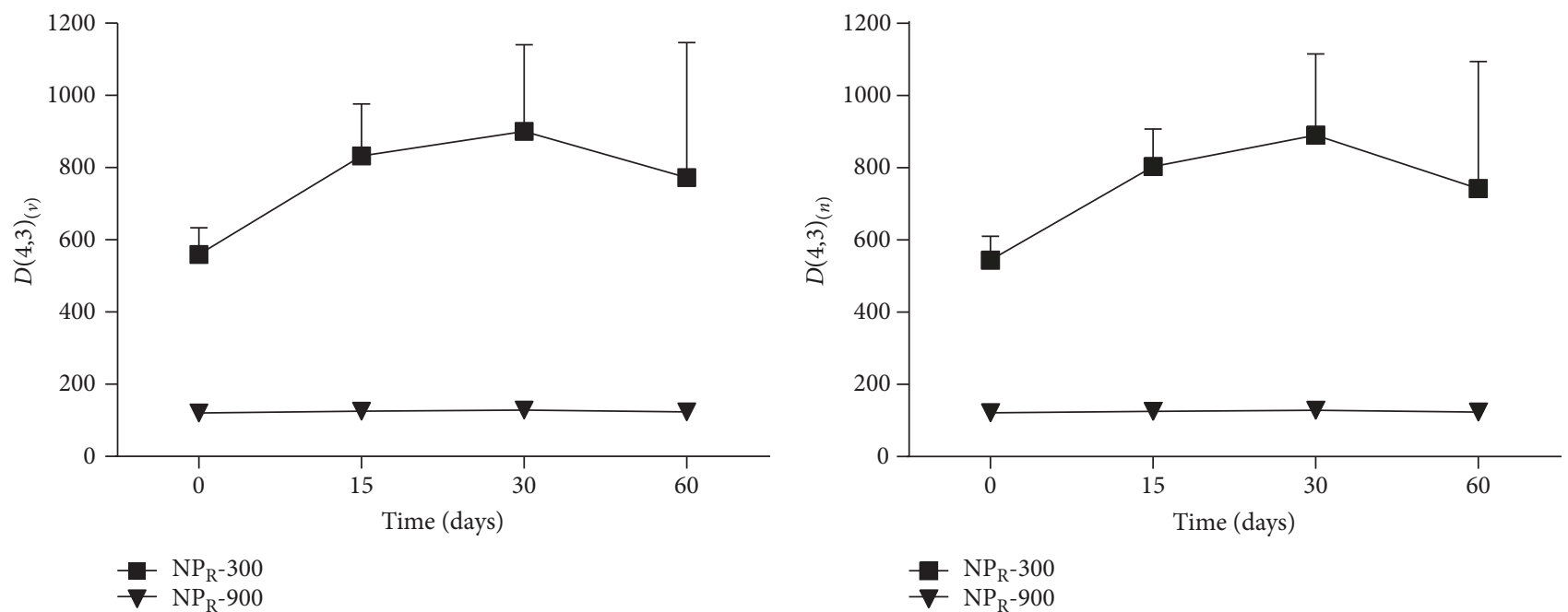

(a)

(b)
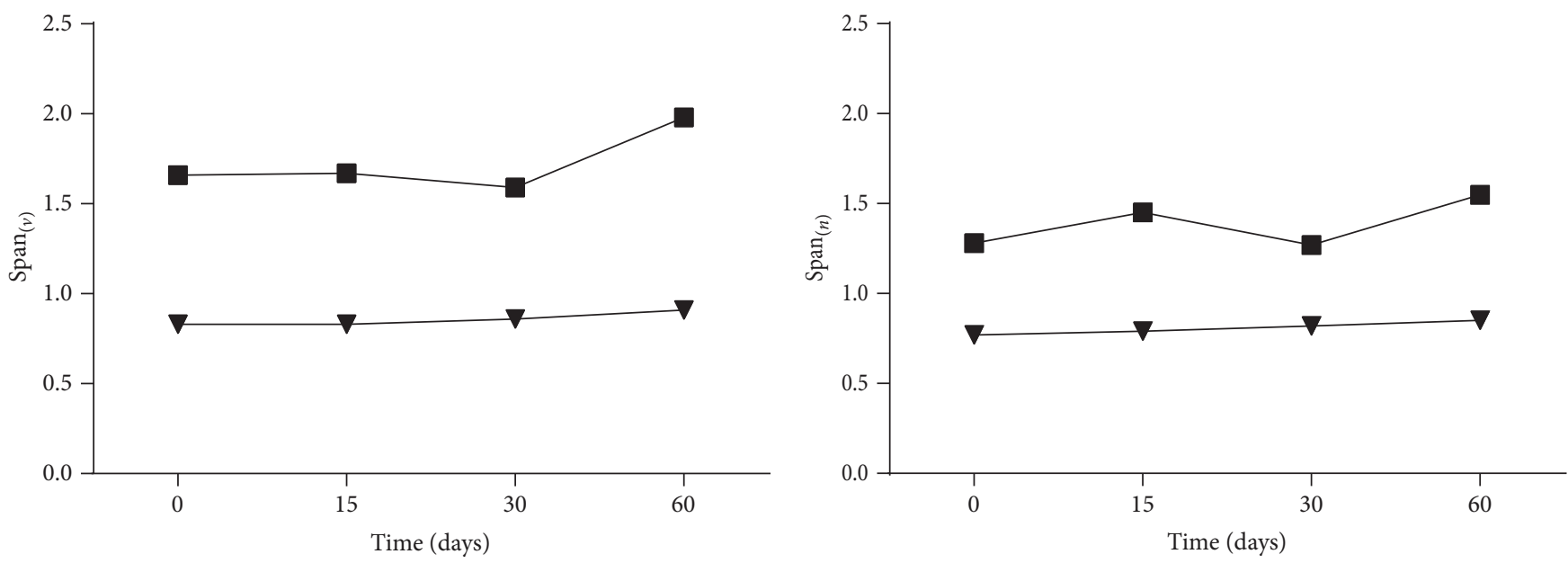

$\rightarrow \mathrm{NP}_{\mathrm{R}}-900$

$\underset{-1}{-} \mathrm{NP}_{\mathrm{R}}-300$
$\rightarrow-\mathrm{NP}_{\mathrm{R}}-900$

(c)

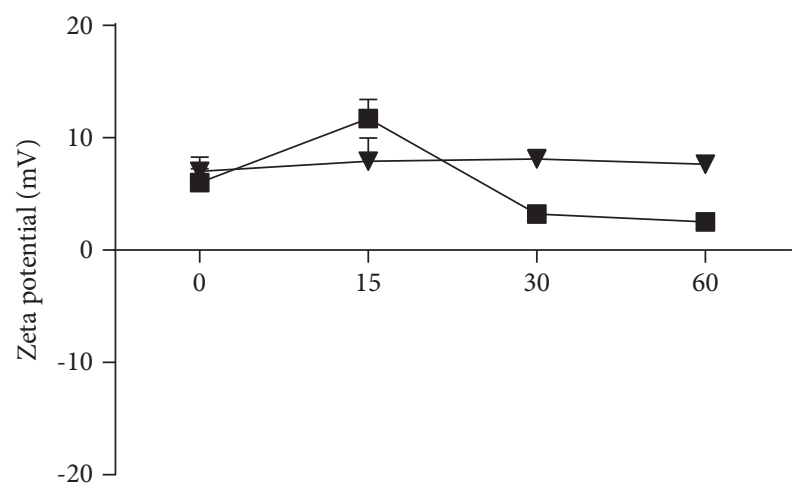

Time (days)

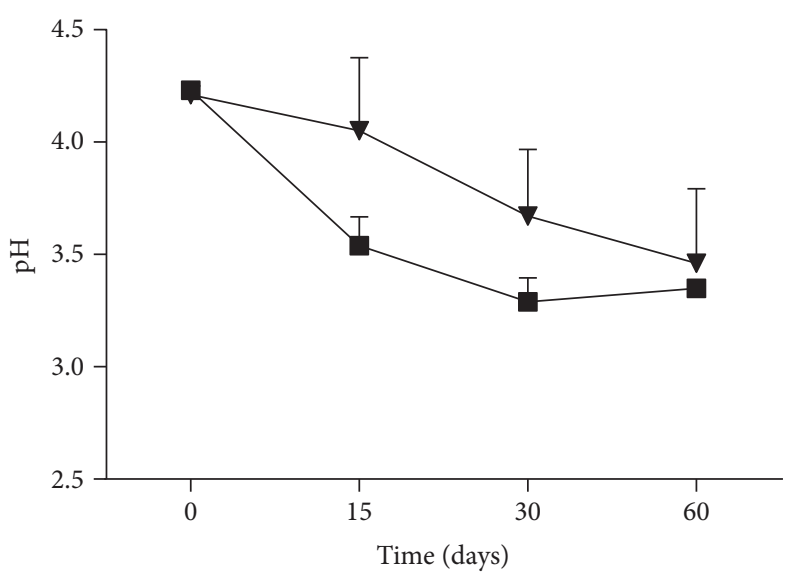

- $\mathrm{NP}_{\mathrm{R}}-300$

$\rightarrow-\mathrm{NP}_{\mathrm{R}}-900$

$\simeq \mathrm{NP}_{\mathrm{R}}-300$

- $\mathrm{NP}_{\mathrm{R}}-900$

(e)

Figure 2: Continued. 


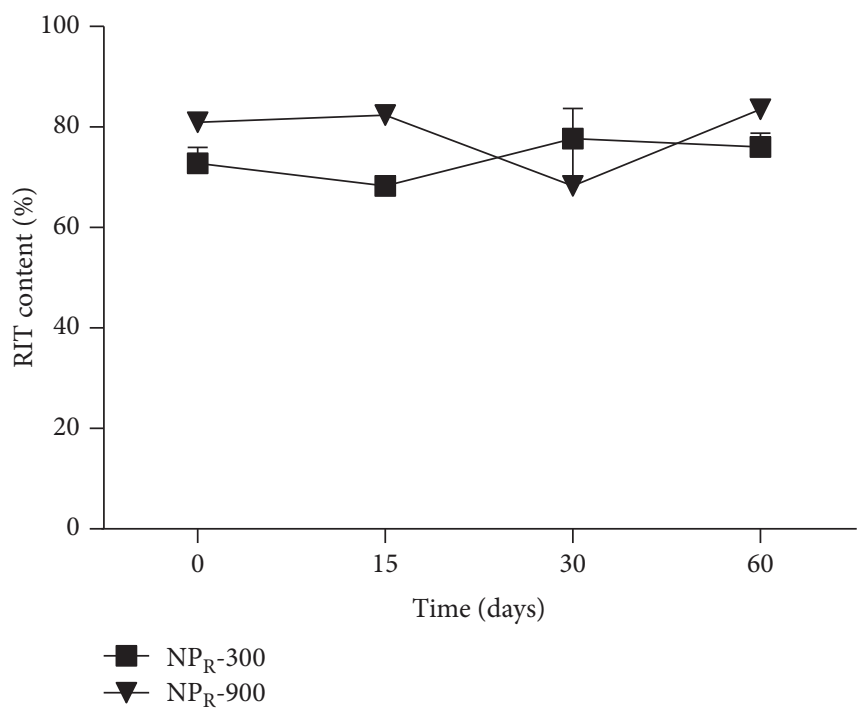

(g)

Figure 2: Mean diameter $(D(3,4))$ by volume (a) and by number of particles (b), size distribution values (Span) by volume (c) and by number of particles (d), zeta potential (e), $\mathrm{pH}(\mathrm{f})$, and RIT content $(\mathrm{g})$ of nanoparticles at times $0,15,30$, and 60 days $\left(\mathrm{NP}_{\mathrm{R}}=\right.$ nanoparticles containing ritonavir, RIT = ritonavir)

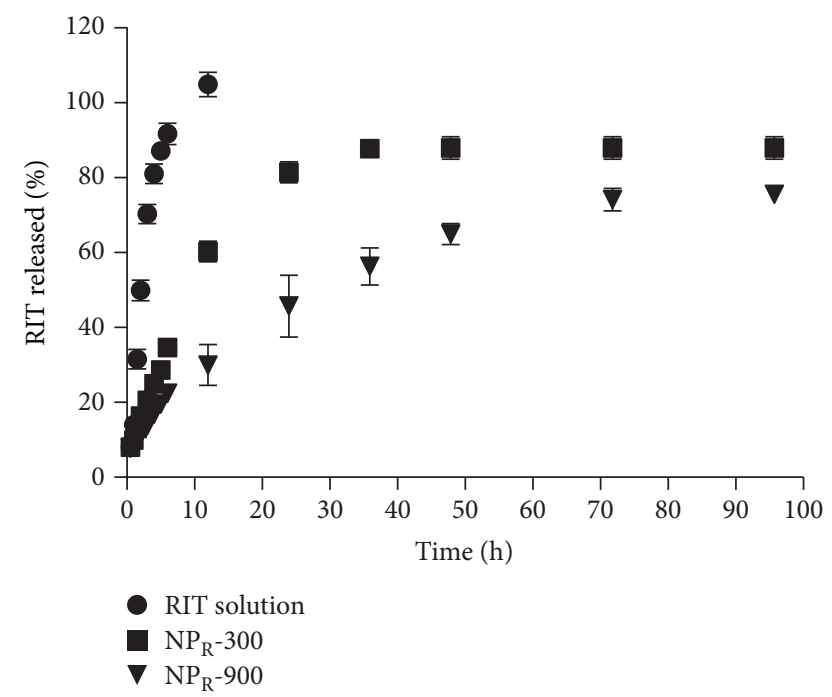

FIGURE 3: In vitro RIT release profiles from nanoparticles $\left(\mathrm{NP}_{\mathrm{R}}-300\right.$ and $\left.\mathrm{NP}_{\mathrm{R}}-900\right)$ and RIT methanolic solution $\left(\mathrm{NP}_{\mathrm{R}}=\right.$ nanoparticles containing ritonavir, RIT = ritonavir).

TABLE 3: Correlation coefficient $(r)$, model selection criterion (MSC), and apparent kinetic constant $(k)$ data fitted by the monoexponential equation $\left(\mathrm{NP}_{\mathrm{R}}=\right.$ nanoparticles containing ritonavir, $\mathrm{RIT}=$ ritonavir $)$.

\begin{tabular}{lccc}
\hline Formulation & $r$ & MSC & $k\left(\mathrm{~min}^{-1}\right)$ \\
\hline RIT solution & $0.9937 \pm 0.0017$ & $2.73 \pm 0.24$ & $0.0049^{\mathrm{a}} \pm 0.0014$ \\
$\mathrm{NP}_{\mathrm{R}}-300$ & $0.9969 \pm 0.0420$ & $3.95 \pm 0.38$ & $0.0011^{\mathrm{b}} \pm 0.0001$ \\
$\mathrm{NP}_{\mathrm{R}}-900$ & $0.9824 \pm 0.0016$ & $2.17 \pm 0.10$ & $0.0004^{\mathrm{b}} \pm 0.0001$ \\
\hline
\end{tabular}
${ }^{a-b}$ Different letters within the same column indicate significant differences at
$p<0.05$.
$\mathrm{NP}_{\mathrm{B}}-900$ after the contact with mucin was $723 \pm 25 \mathrm{~nm}$ and $0.6 \pm 0.07$, and $154 \pm 6.3 \mathrm{~nm}$ and $0.30 \pm 0.02$, respectively. These values are significantly higher than those observed before the contact $(p<0.05)$ and resulted in MI values of 1.26 and 1.25 for $\mathrm{NP}_{\mathrm{B}}-300$ and $\mathrm{NP}_{\mathrm{B}}-900$, respectively. The results indicate that mucin is partially adsorbed on the nanoparticle surface, while a remaining amount was kept free in the solution. The free mucin is related to the micrometer peak and the high heterogeneity of size distribution, as demonstrated by the increased value of PDI.

The zeta potential value of the mucin solution was $-15.3 \pm 1.7 \mathrm{mV}$. The negative charge of mucin is related to sialic acid residues linked to the terminal ends of the oligosaccharide chains of the molecule $[16,17,28]$. As previously discussed, $\mathrm{NP}_{\mathrm{B}}-300$ and $\mathrm{NP}_{\mathrm{B}}-900$ presented a positive zeta potential. After contact with mucin, the zeta potential values of $3.6 \pm 1.2 \mathrm{mV}$ for $\mathrm{NP}_{\mathrm{B}}-300$ and $0.5 \pm 0.9 \mathrm{mV}$ for $\mathrm{NP}_{\mathrm{B}}-900$ were significantly lower than the previous ones $(p<0.05)$. The neutralization of the positive charge occurred by electrostatic attraction with the negative charge of mucin, as described for the electronic theory $[17,26]$.

The ability to interact with mucin presented by nanoparticles demonstrates their mucoadhesive properties. The mechanism of nanoparticle adhesion cannot be justified in one way, since particles can be negatively or positively adsorbed in the mucus. Thus, there is probably a dynamic balance between electrostatic interactions and other mechanisms, such as diffusion and physical entanglement $[26,29]$.

Considering the relatively short gastrointestinal (GI) time, the mucoadhesion phenomenon is very important, because it leads to the improvement of significant drug localization for oral sustained delivery [30, 31]. Thus, it is suggested that the release time presented by nanoparticles should not be an obstacle to the absorption of RIT against the time of gastric emptying $(0.5-4 \mathrm{~h})$. In addition, EUD is 


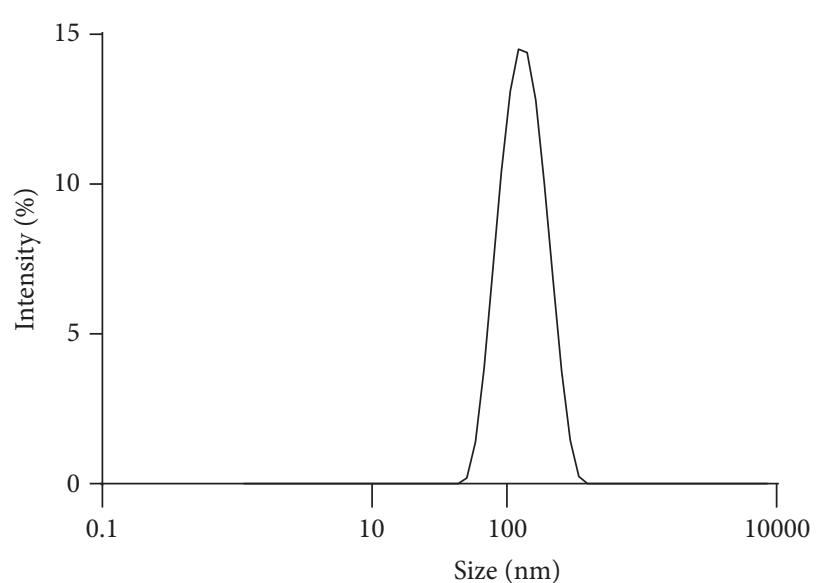

(a)

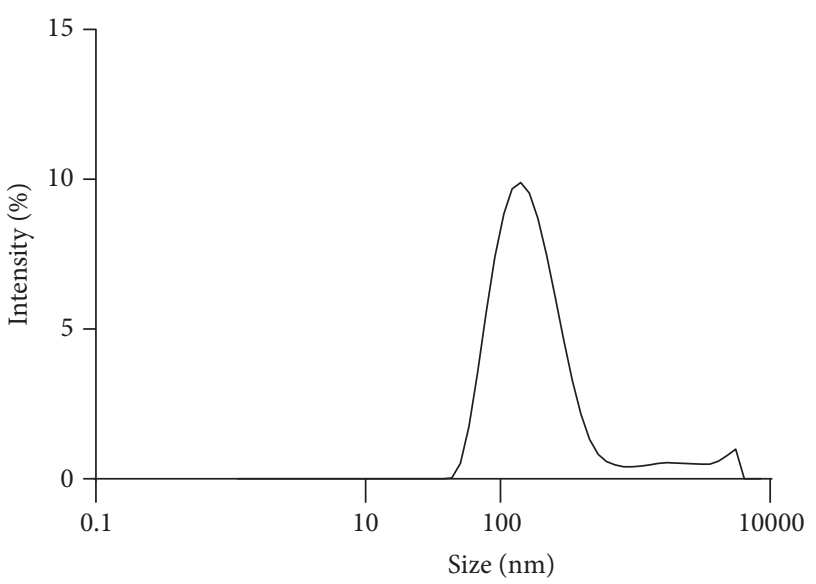

(b)

FIGURE 4: Size distribution of $\mathrm{NP}_{\mathrm{B}}-900$ before (a) and after (b) interaction with mucin $\left(\mathrm{NP}_{\mathrm{B}}=\right.$ nanoparticles without ritonavir).

an independent $\mathrm{pH}$ polymer, so it is suggested that ritonavir also exhibits a similar release into the intestine, which has a longer emptying time (1-24h) [31].

3.6. Taste Evaluation In Vivo. The bitter taste is reported through patient complaints on antiretroviral drugs, mainly of the protease inhibitor class, such as RIT [32]. In a study carried out by Lin et al. [33] on the taste effect of antiretroviral drugs on adherence to treatment of HIV-infected children, the RIT was the least palatable drug with consumption refused by $50 \%$ of the children, this being an independent predictor of drug and therapy discontinuation because of poor taste. Considering the importance of palatability in the therapeutic adherence by children and the negative impacts on adherence generated by poor palatability of antiretroviral drugs [32-34], a discriminatory sensory analysis through a human panel was carried out with RIT nanoparticle formulations and RIT solution.

A survey of volunteers averaging 27.2 years of age (a range of 20-33 years of age) was conducted to evaluate the bitter taste of the formulations containing RIT, and they were graded as follows: bitterness not detectable, slightly bitter, bitter, or very bitter. For $\mathrm{NP}_{\mathrm{R}}-900$ as well as for the RIT ethanolic solution, the predominant taste felt by $80 \%$ and $70 \%$ of the panelists was slightly bitter (Figure 5 ). However, for $\mathrm{NP}_{\mathrm{R}}-300,70 \%$ of the panelists felt a predominating very bitter taste.

The results demonstrated the influence exerted by the formulation on the taste of RIT. The $\mathrm{NP}_{\mathrm{R}}-900$ formulation showed less bitter taste than the $\mathrm{NP}_{\mathrm{R}}-300$ formulation, which shows that the main parameter influencing the taste was the particle size, since $\mathrm{NP}_{\mathrm{R}}-900$ presented smaller particle size distribution and better particle size homogeneity.

Regarding the RIT solution, the results showed that most panelists felt a slight bitter taste, that is, a taste similar to $\mathrm{NP}_{\mathrm{R}}-900$ and better than $\mathrm{NP}_{\mathrm{R}}-300$. The dominant burning sensation elicited by ethanol may have interfered in the analysis, being responsible for the nonpalatability of the bitter taste of the drug and of ethanol itself [35].

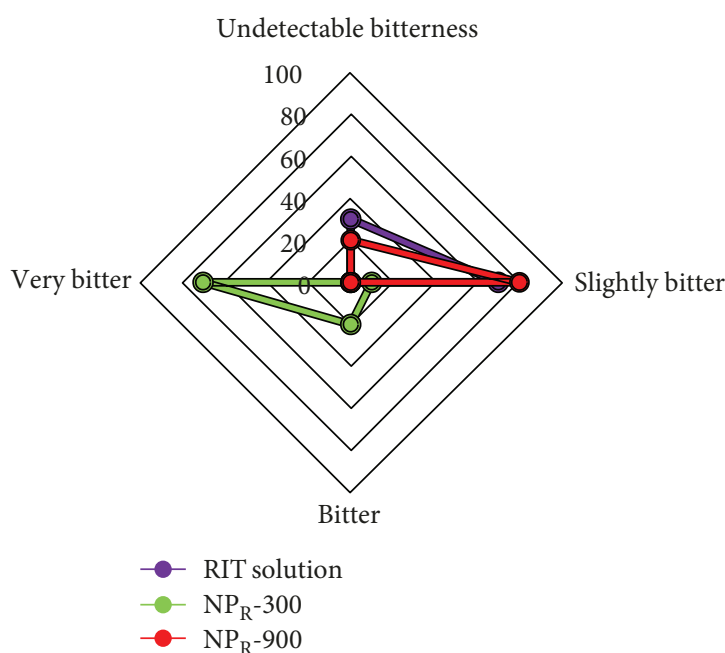

FIGURE 5: In vivo sensory panel chart of RIT solution, $\mathrm{NP}_{\mathrm{R}}-300$, and $\mathrm{NP}_{\mathrm{R}}-900\left(\mathrm{NP}_{\mathrm{R}}=\right.$ nanoparticles containing ritonavir, $\mathrm{RIT}=$ ritonavir $)$.

The ability of the human sensory panel to detect large variations of taste was demonstrated mainly by $\mathrm{NP}_{\mathrm{R}}-300$. However, this study had some limitations, as volunteers are not trained and tend to not detect subtle variations. This was made explicit in the small taste variations shown between $\mathrm{NP}_{\mathrm{R}}-900$ and the RIT solution. Other limitations are the individual genetic differences between the individuals and that the volunteers do not have the same sensory experience as children tasting the liquid formulation [36].

\section{Conclusion}

Polymer-based matricial nanostructures for ritonavir incorporation were successfully developed through the technique of interfacial deposition of a preformed polymer. The nanostructures prepared with Eudragit ${ }^{\circledast}$ RS100 and Polycaprolactone triol $900\left(\mathrm{NP}_{\mathrm{R}}-900\right)$ were stable for 60 days and showed a greater control of the drug release and a less bitter taste, compared to nanoparticles prepared with Eudragit ${ }^{\circledR}$ RS100 
and Polycaprolactone triol $300\left(\mathrm{NP}_{\mathrm{R}}-300\right)$, which showed phase separation after 15 days under storage. Both formulations presented similar mucoadhesive properties. $\mathrm{NP}_{\mathrm{R}}-900$ was the most promising nanoparticle formulation for oral delivery of ritonavir.

\section{Data Availability}

The data used to support the findings of this study are available from the corresponding author upon request.

\section{Conflicts of Interest}

The authors report no declarations of interest.

\section{Acknowledgments}

This research was financially supported by CNPq, Brasil (scholarship of Mosiele Giaretta and approved project number 477196/2013-6). This study was financed in part by the Coordenação de Aperfeiçoamento de Pessoal de Nível Superior, Brasil (CAPES)_Finance Code 001. We acknowledge Cristalia for Ritonavir donation and Evonik for Eudragit $^{\circledR}$ RS100 donation. We thank Dr. Silvia Stanisçuaski Guterres and Dr. Adriana Raffin Pohlmann, Universidade Federal do Rio Grande do Sul, for access to the equipments for nanoparticle production and characterization.

\section{References}

[1] WHO and World Health Organization, Global Health Sector Strategy on HIV 2016-2021, Who Document Production Services, Geneva, Switzerland, 2017.

[2] R. S. Kuchenbecker, "Antivirais," in Farmacologia ClínicaFundamentos da Terapêutica Racional, F. D. Fuchs and L. Wannmacher, Eds., pp. 392-399, Guanabara Koogan, Rio de Janeiro, 3 edition, 2004.

[3] A. Sosnik, D. A. Chiappetta, and A. M. Carcaboso, "Drug delivery systems in HIV pharmacotherapy: what has been done and the challenges standing ahead," Journal of Controlled Release, vol. 138, no. 1, pp. 2-15, 2009.

[4] R. H. Müller, K. Mäder, and S. Gohla, "Solid lipid nanoparticles (SLN) for controlled drug delivery-a review of the state of the art," European Journal of Pharmaceutics and Biopharmaceutics, vol. 50, no. 1, pp. 161-177, 2000.

[5] P. M. Dandagi, S. P. Rath, A. P. Gadad, and V. S. Mastiholimath, "Taste masked quinine sulphate loaded solid lipid nanoparticles for flexible pediatric dosing," Indian Journal of Pharmaceutical Education and Research, vol. 48, pp. 93-99, 2014.

[6] I. Lozoya-Agullo, F. Araújo, I. González-Álvarez et al., "PLGA nanoparticles are effective to control the colonic release and absorption on ibuprofen," European Journal of Pharmaceutical Sciences, vol. 115, pp. 119-125, 2018.

[7] M. Saravanan, T. Asmalash, A. Gebrekidan et al., "Nanomedicine as a newly emerging approach to combat human immunodeficiency virus (HIV)," Pharmaceutical Nanotechnology, vol. 6, no. 1, pp. 17-27, 2018.

[8] Y. Gao, J. C. Kraft, D. Yu, and R. J. Y. Ho, "Recent developments of nanotherapeutics for targeted and long-acting, combination HIV chemotherapy," European Journal of Pharmaceutics and Biopharmaceutics, 2018, In Press.
[9] A. Sonje and A. Chandra, "Comprehensive review on Eudragit polymers," International Research Journal of Pharmacy, vol. 4, no. 5, pp. 71-74, 2013.

[10] K. Dillen, J. Vandervoort, G. van den Mooter, and A. Ludwig, "Evaluation of ciprofloxacin-loaded Eudragit ${ }^{\circledR}$ RS100 or RL100/PLGA nanoparticles," International Journal of Pharmaceutics, vol. 314, no. 1, pp. 72-82, 2006.

[11] B. Balzus, F. F. Sahle, S. Hönzke et al., "Formulation and ex vivo evaluation of polymeric nanoparticles for controlled delivery of corticosteroids to the skin and the corneal epithelium," European Journal of Pharmaceutics and Biopharmaceutics, vol. 115, pp. 122-130, 2017.

[12] L. A. Kanis, M. Generoso, and V. Soldi, "Filmes de poli (etileno-co-metil acrilato)/poli (caprolactona triol): caracterização e propriedades mecânicas," Latin American Journal of Pharmacy, vol. 26, no. 5, pp. 700-705, 2007.

[13] M. Moazeni, H. R. Kelidari, M. Saeedi et al., "Time to overcome fluconazole resistant Candida isolates: solid lipid nanoparticles as a novel antifungal drug delivery system," Colloids and Surfaces B: Biointerfaces, vol. 142, pp. 400407, 2016.

[14] S. S. Santos, A. Lorenzoni, L. M. Ferreira et al., "Clotrimazoleloaded Eudragit ${ }^{\circledR}$ RS100 nanocapsules: preparation, characterization and in vitro evaluation of antifungal activity against Candida species," Materials Science \& Engineering, C: Materials for Biological Applications, vol. 33, no. 3, pp. 1389-1394, 2013.

[15] H. Fessi, F. Puisieux, J. P. Devissaguet, N. Ammoury, and S. Benita, "Nanocapsule formation by interfacial polymer deposition following solvent displacement," International Journal of Pharmaceutics, vol. 55, no. 1, pp. R1-R4, 1989.

[16] A. Sosnik, J. C. Imperiale, B. Vázquez-González et al., "Mucoadhesive thermo-responsive chitosan-g-poly(N-isopropylacrylamide) polymeric micelles via a one-pot gammaradiation-assisted pathway," Colloids and Surfaces B: Biointerfaces, vol. 136, pp. 900-907, 2015.

[17] P. dos Santos Chaves, A. F. Ourique, L. A. Frank, A. R. Pohlmann, S. S. Guterres, and R. C. R. Beck, "Carvedilolloaded nanocapsules: mucoadhesive properties and permeability across the sublingual mucosa," European Journal of Pharmaceutics and Biopharmaceutics, vol. 114, pp. 88-95, 2017.

[18] R. V. Contri, M. Kaiser, F. S. Poletto, A. R. Pohlmann, and S. S. Guterres, "Simultaneous control of capsaicinoids release from polymeric nanocapsules," Journal of Nanoscience and Nanotechnology, vol. 11, no. 3, pp. 2398-2406, 2011.

[19] V. K. Nikam, K. B. Kotade, V. M. Gaware et al., "Eudragit a versatile polymer: a review," Pharmacology, vol. 1, pp. 152$164,2011$.

[20] S. P. Vyas, R. Subhedar, and S. Jain, "Development and characterization of emulsomes for sustained and targeted delivery of an antiviral agent to liver," The Journal of Pharmacy and Pharmacology, vol. 58, no. 3, pp. 321-326, 2006.

[21] M. D. Bianchin, I. C. Külkamp-Guerreiro, C. P. de Oliveira, R. V. Contri, S. S. Guterres, and A. R. Pohlmann, "Radar charts based on particle sizing as an approach to establish the fingerprints of polymeric nanoparticles in aqueous formulations," Journal of Drug Delivery Science and Technology, vol. 30, pp. 180-189, 2015.

[22] L. Fiel, R. Contri, J. Bica et al., "Labeling the oily core of nanocapsules and lipid-core nanocapsules with a triglyceride conjugated to a fluorescent dye as a strategy to particle 
tracking in biological studies," Nanoscale Research Letters, vol. 9, no. 1, p. 233, 2014.

[23] S. Guo, K. Pham, D. Li, S. Penzak, and X. Dong, "Novel in situ self-assembly nanoparticles for formulating a poorly watersoluble drug in oral solid granules, improving stability, palatability, and bioavailability," International Journal of Nanomedicine, vol. 11, pp. 1451-1460, 2016.

[24] K. S. Rao, M. K. Reddy, J. L. Horning, and V. Labhasetwar, "TAT-conjugated nanoparticles for the CNS delivery of anti-HIV drugs," Biomaterials, vol. 29, no. 33, pp. 44294438, 2008.

[25] C. J. Destache, T. Belgum, K. Christensen, A. Shibata, A. Sharma, and A. Dash, "Combination antiretroviral drugs in PLGA nanoparticle for HIV-1," BMC Infectious Diseases, vol. 9, no. 1, p. 198, 2009.

[26] A. Sosnik, J. Das Neves, and B. Sarmento, "Mucoadhesive polymers in the design of nano-drug delivery systems for administration by non-parenteral routes: a review," Progress in Polymer Science, vol. 39, no. 12, pp. 2030-2075, 2014.

[27] B. J. Teubl, M. Absenger, E. Fröhlich, G. Leitinger, A. Zimmer, and E. Roblegg, "The oral cavity as a biological barrier system: design of an advanced buccal in vitro permeability model," European Journal of Pharmaceutics and Biopharmaceutics, vol. 84, no. 2, pp. 386-393, 2013.

[28] R. J. Glisoni, S. S. Quintana L, M. Molina, M. Calderón, A. G. Moglioni, and A. Sosnik, "Chitosan-g-oligo(epsiloncaprolactone) polymeric micelles: microwave-assisted synthesis and physicochemical and cytocompatibility characterization," Journal of Materials Chemistry B, vol. 3, no. 24, pp. 4853-4864, 2015.

[29] J. Grießinger, S. Dünnhaupt, B. Cattoz et al., "Methods to determine the interactions of micro- and nanoparticles with mucus," European Journal of Pharmaceutics and Biopharmaceutics, vol. 96, pp. 464-476, 2015.

[30] S. Mansuri, P. Kesharwani, K. Jain, R. K. Tekade, and N. K. Jain, "Mucoadhesion: a promising approach in drug delivery system," Reactive and Functional Polymers, vol. 100, pp. 151172, 2016.

[31] A. Sosnik and R. Augustine, "Challenges in oral drug delivery of antiretrovirals and the innovative strategies to overcome them," Advanced Drug Delivery Reviews, vol. 103, pp. 105-120, 2016.

[32] S. S. Schiffman, J. Zervakis, S. Heffron, and A. E. Heald, "Effect of protease inhibitors on the sense of taste," Nutrition, vol. 15, no. 10 , pp. $767-772,1999$.

[33] D. Lin, J. A. Seabrook, D. M. Matsui, S. M. King, M. J. Rieder, and Y. Finkelstein, "Palatability, adherence and prescribing patterns of antiretroviral drugs for children with human immunodeficiency virus infection in Canada," Pharmacoepidemiology and Drug Safety, vol. 20, no. 12, pp. 1246-1252, 2011.

[34] L. Wang, Y. Sun, C. Kuang, and X. Zhang, "Preparation and evaluation of taste masked oral suspension of arbidol hydrochloride," Asian Journal of Pharmaceutical Sciences, vol. 10, no. 1, pp. 73-79, 2015.

[35] A. A. Nolden, J. E. McGeary, and J. E. Hayes, "Differential bitterness in capsaicin, piperine, and ethanol associates with polymorphisms in multiple bitter taste receptor genes," Physiology \& Behavior, vol. 156, pp. 117-127, 2016.

[36] J. A. Mennella, P. S. Mathew, and E. D. Lowenthal, "Use of adult sensory panel to study individual differences in the palatability of a pediatric HIV treatment drug," Clinical Therapeutics, vol. 39, no. 10, pp. 2038-2048, 2017. 


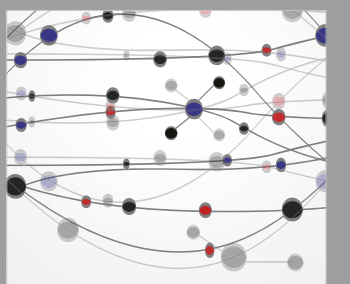

The Scientific World Journal
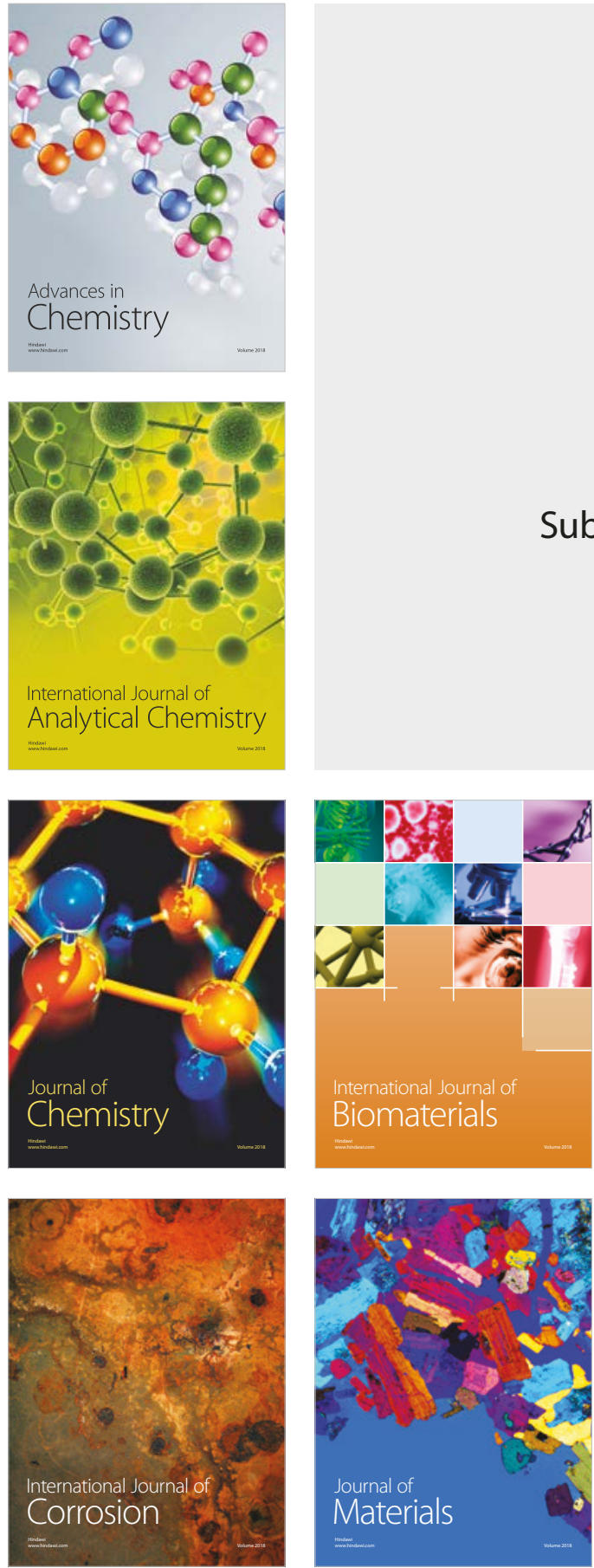

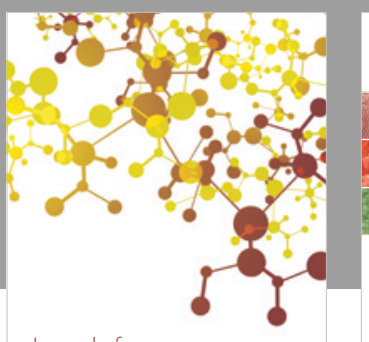

Journal of

Applied Chemistry
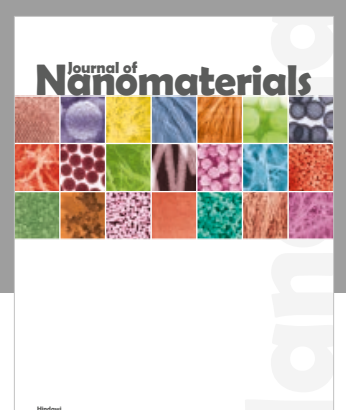

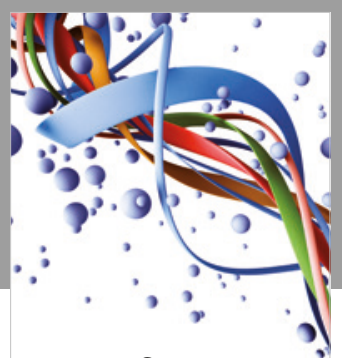

Scientifica

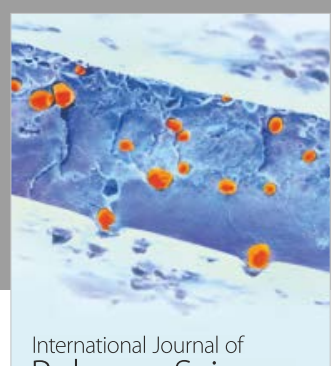

Polymer Science

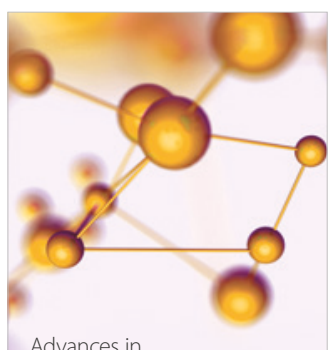

Physical Chemistry
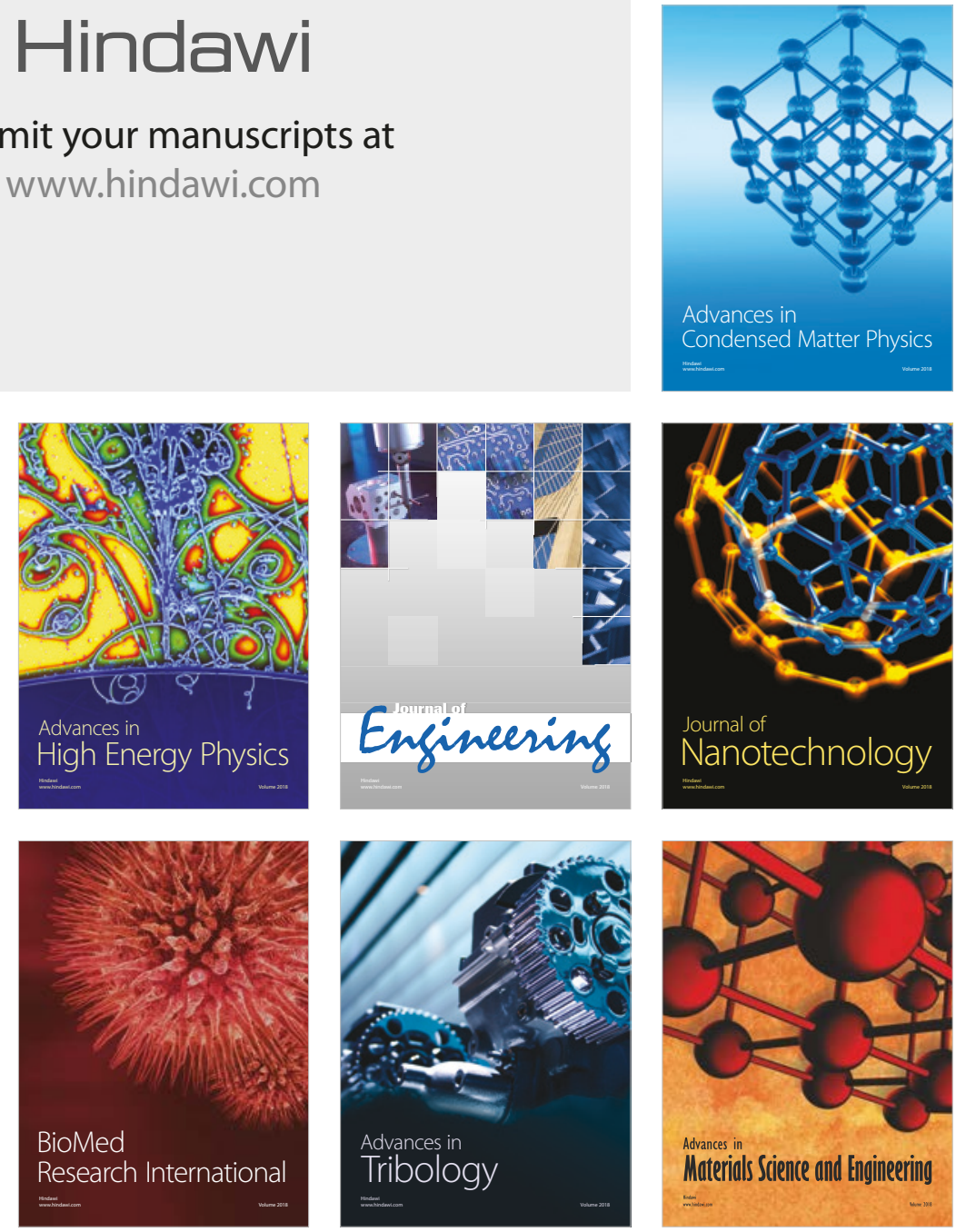